\title{
Studies of effect of heterocyclic dyes in photogalvanic cells for solar energy conversion and storage: NaLS-ascorbic acid system
}

\author{
K R GENWA* and ANJU CHOUHAN \\ Department of Chemistry, Jai Narain Vyas University, Jodhpur 342 001, India \\ e-mail: krg2004@ rediffmail.com
}

MS received 3 March 2004; revised 12 September 2004

\begin{abstract}
The photogalvanic effect has been studied in three systems using photogalvanic cells and NaLS-ascorbic acid-azur A, NaLS-ascorbic acid-azur B, NaLS-ascorbic acid-azur C systems. The photopotential and photocurrent generated by these systems are $770 \cdot 0,971 \cdot 0,623.0 \mathrm{mV}$ and $160 \cdot 0,185 \cdot 0$, $145.0 \mu \mathrm{A}$ respectively. The effects of different parameters on the electrical outputs of the cell have been observed and current-voltage characteristics of the cell studied, and a mechanism has been proposed for the generation of photocurrent in photogalvanic cells. The conversion efficiencies for azur A, azur B and azur $\mathrm{C}$ are $0.5461,0.9646$ and $0.4567 \%$ and storage capacity 110,135 and 95 min respectively.
\end{abstract}

Keywords. Photogalvanic cell; heterocyclic dyes; azur A; azur B; azur C; NaLS; ascorbic acid; fill factor; conversion efficiency.

\section{Introduction}

The photogalvanic effect was first observed by Rideal and Williams ${ }^{1}$, systematically investigated by Rabinowitch $^{2,3}$ and later by various other workers. ${ }^{4-8}$ Hoffman and Lichtin ${ }^{9}$ have discussed various problems encountered in the development of this field. A detailed literature survey reveals that different photosensitizers have been used in photogalvanic cells along with reductants and surfactants. ${ }^{10-15}$ Recently, Gangotri et $a l^{16-20}$ observed the photogalvanic effect in cells containing dyes, reductants and surfactants, but negligible attention has been paid to the use of heterocyclic dye (azur A, azur B, azur C) in photogalvanic cells with ascorbic acid and NaLS for solar energy conversion and storage and therefore, the present work was undertaken.

\section{Experimental}

Ascorbic acid (Loba), sodium lauryl sulphate (Loba), azur A (Loba), azur B (Sd fine chemicals), azur C (Sigma) and sodium hydroxide ( $\mathrm{Sd}$ fine chemicals) were used in the present work. All solutions were prepared in doubly distilled water and were kept in amber-coloured containers for protect in from sun-

\footnotetext{
*For correspondence
}

light. Concentrations of azur A, azur B and azur C dyes used were $8.0 \times 10^{-5}, 9.5 \times 10^{-5}, 1.6 \times 10^{-4} \mathrm{M}$ respectively. A mixture of solutions of dye, reductant, surfactant and sodium hydroxide was taken in an $\mathrm{H}$ type glass tube. A platinum electrode $\left(1.0 \times 1.0 \mathrm{~cm}^{2}\right)$ was immersed in one limb of the H-tube and a saturated calomel electrode (SCE) was immersed in the other limb of. The whole system was first placed in the dark till a stable potential was attained, then the limb containing the platinum electrode was exposed to a $200 \mathrm{~W}$ tungsten lamp (Philips), while the other with the SCE was kept in the dark. A water filter was used to cut off thermal radiations.

Photochemical bleaching of the dyes was studied potentiometrically. A digital $\mathrm{pH}$ meter (Systronics 335) and a microammeter (INCO-65) were used to measure the potential and current generated by the system respectively. The current-voltage characteristics were studied by applying an external load with the help of a carbon pot $(\log 500 \mathrm{~K})$ connected in the circuit.

\section{Significant observation of systems}

Our effort is aimed at bringing down the comparative cost of solar cells. For this purpose easily available, stable, low cost and indigenous materials should be used and, hence, suitable heterocyclic dyes, reductants 
and surfactants have been selected for the present investigation.

The chief observations about different systems are given in table 4 below. These reflect the overall outcome of the present studies, and justify the significance of these cells from the solar energy conversion and storage point of view.

\section{Effect of variation of $\mathrm{pH}$}

It is seen that all the three systems with heterocyclic dye work effectively in the strong alkaline range. The working range for the present work was $\mathrm{pH}=$ $11 \cdot 6-13 \cdot 2$. The potential of the system is found to increase as the $\mathrm{pH}$ increases, reaching a maximum value for a particular $\mathrm{pH}$, and then decreases on further increases in $\mathrm{pH}$.

It is quite interesting to observe that $\mathrm{pH}$ at the optimum condition for reductant has a relation with its $\mathrm{p} K a$ value, i.e. the desired $\mathrm{pH}$ should be slightly higher than their $\mathrm{p} K a$ values $(\mathrm{pH}=\mathrm{p} K a+1$ to 3$)$.

\section{Effect of dyes}

In the present work, three different types of heterocyclic dyes (azur A, B and C) were used in photogalvanic cells containing the NaLS-ascorbic acid system.

The effects of variation of concentration of the three heterocyclic dyes have been studied. It is observed that there is an increase in photopotential and photocurrent values on increasing the concentration of the dyes. It is necessary to keep the concentration at $10^{-5}, 10^{-5}, 10^{-4} \mathrm{M}$ for azur $\mathrm{A}$, azur $\mathrm{B}$ and azur $\mathrm{C}$ respectively, for effective results in electrical output. The heterocyclic dye azur B is the most efficient dye, followed by azur A and azur C, for generation of electrical output, conversion efficiency and storage point of view due to presence of the trimethyl group.

On the lower side of the concentration range of dyes, there are a limited number of dyes molecules to absorb the major portion of the light in the path and, therefore, there is low electrical output, whereas

Table 1. Probable electroactive species.

\begin{tabular}{ll}
\hline $\begin{array}{l}\text { In illuminated chamber } \\
\text { Dye }\end{array}$ & $\begin{array}{l}\text { In dark chamber } \\
\text { Oxidized form of reductant } \\
\left(\mathrm{R}^{+}\right)\end{array}$ \\
Oxidized form of reductant \\
$\left(\mathrm{R}^{+}\right)$ \\
Semi or leuco form of dye & Dye \\
\hline
\end{tabular}

a higher concentration of dyes does not permit the desired light intensity to reach the molecules near the electrodes and hence, there is corresponding fall in the power of the cell.

\section{Effect of diffusion length}

Effect of variation of diffusion length on the electrical output $\left(i_{\max }, i_{\text {eq }}\right)$ and initial rate of generation of current of the photogalvanic cell were observed by using $\mathrm{H}$-cells of different dimensions. The diffusion length (distance between the electrodes) greatly affects all the three systems. It is observed that in the first few minutes of illumination there is sharp increase in the photocurrent and then there is gradual decrease to a stable value of photocurrent. This behaviour of photocurrent indicates an initial rapid reaction followed by a slow rate-determining step. The results are also discussed to know about electroactive species by considering various probable processes and combinations of electroactive species for the electrical output of photogalvanic cells. These processes and combinations are summarized in table 1 .

The oxidized form of the reductant is formed only in the illuminated chamber and if it is taken to be the electractive species in dark chamber, then it must diffuse from the illuminated chamber to the dark chamber to accept an electron from the electrode. As a consequence, the maximum photocurrent $\left(i_{\max }\right)$ and rate of generation of photocurrent should increase with increase in diffusion length, but this is not observed experimentally. The value of $\left(i_{\text {eq }}\right)$ is also observed to be independent with respect to change in diffusion length (rather it decreases slightly). Therefore, it may be concluded that the main electroactive species are the leuco or semi leuco form of dyes (photosensitizers) and the dye in the illuminated and the dark chamber respectively. The reductant and its oxidation product act only as electron carriers in the path.

\section{Effect of temperature}

Photopotentials and photocurrents of photogalvanic cells have been measured at different temperatures and the effect of temperature on electrical output in all three systems has been studied.

On the basis of the obtained results it is clear that there is a linear relation between electrical output of the cell and temperature. It is also observed that on increasing temperature, the photo current increases 
Table 2. Effect of temperature.

$[\operatorname{azur} \mathrm{A}]=8.0 \times 10^{-5} \mathrm{M}$; $\left[\right.$ azur B] $=9.6 \times 10^{-5} \mathrm{M}$; $\left[\right.$ azur C] $=1.6 \times 10^{-4} \mathrm{M} ;[\mathrm{NaLS}]=6.0 \times$ $10^{-3} \mathrm{M}$; [ascorbic acid] $=4.8 \times 10^{-3} \mathrm{M}$; light intensity $=10 \cdot 4 \mathrm{~m} \mathrm{~W} \mathrm{~cm}^{-2} ; \mathrm{pH}=12 \cdot 4$; temp. $=$ $303 \mathrm{~K}$

\begin{tabular}{cccccc}
\hline & \multicolumn{5}{c}{ Temperature $(\mathrm{K})$} \\
\cline { 2 - 5 } NaLS-ascorbic acid system & $298 \cdot 0$ & $303 \cdot 0$ & $308 \cdot 0$ & $313 \cdot 0$ & $318 \cdot 0$ \\
\hline Azur A Photopotential $(\mathrm{mV})$ & $795 \cdot 0$ & $770 \cdot 0$ & $724 \cdot 0$ & $685 \cdot 0$ & $670 \cdot 0$ \\
Photocurrent $(\mu \mathrm{A})$ & $152 \cdot 0$ & $160 \cdot 0$ & $174 \cdot 0$ & $182 \cdot 0$ & $190 \cdot 0$ \\
Azur B Photopotential $(\mathrm{mV})$ & $995 \cdot 0$ & $971 \cdot 0$ & $920 \cdot 0$ & $860 \cdot 0$ & $812 \cdot 0$ \\
Photocurrent $(\mu \mathrm{A})$ & $172 \cdot 0$ & $185 \cdot 0$ & $195 \cdot 0$ & $197 \cdot 0$ & $200 \cdot 0$ \\
Azur C Photopotential $(\mathrm{mV})$ & $650 \cdot 0$ & $623 \cdot 0$ & $601 \cdot 0$ & $580 \cdot 0$ & $525 \cdot 0$ \\
Photocurrent $(\mu \mathrm{A})$ & $138 \cdot 0$ & $145 \cdot 0$ & $150 \cdot 0$ & $158 \cdot 0$ & $165 \cdot 0$ \\
\hline
\end{tabular}
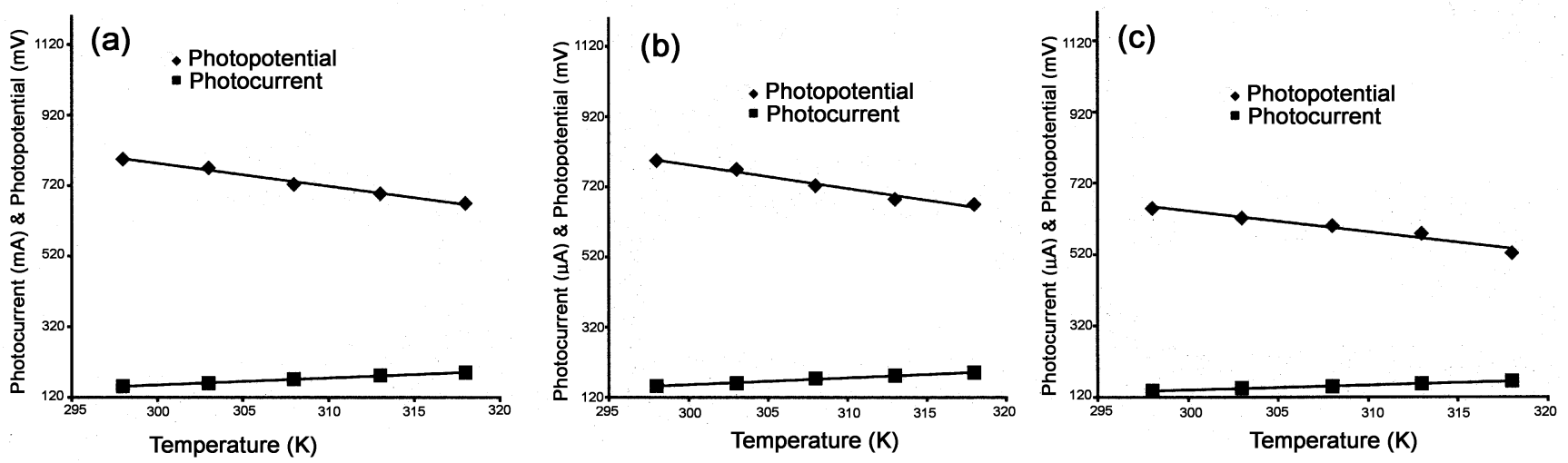

Figure 1. Variation of photocurrent and photopotential with temperature for systems containing NaLS, ascorbic acid and azur A (a), azur B (b) and azur C (c).

but the photopotential decreases. This is due to the fact that internal resistant of the cell decreases at higher temperature resulting in a rise in photocurrent and corresponding there is a fall in photo potential in all the systems. The results are given in table 2 and figure 1.

\section{Effect of light intensity}

Lights source of different intensities (different wattages) were used to observe the effect of light intensity on the output of the cell.

It is observed that the photocurrent shows linearly increasing behaviour with increase in intensity of light, whereas photo potential increases with increasing light intensity in a logarithmic manner (i.e. the plot of $\log V$ vs $i$ is linear). Increasing light intensities increase the number of photons per unit area (incident power) striking the dye molecules around the platinum electrode and, therefore, increase in the electrical output occurs. Increase in light intensity also increases the temperature of the cell and, hence in our experiment a water filter was used to cut off the thermal radiations. The results are given in table 3 and also presented in figure 2 .

\section{9. $i-V$ Characteristics of the cell}

A digital $\mathrm{pH}$ meter was used to measure the open circuit voltage $\left(V_{\text {oc }}\right)$ (keeping the other circuit open) whereas short circuit current $\left(i_{\mathrm{sc}}\right)$ was measured with a microammeter (keeping the other circuit closed). The electrical parameters between these two extreme values $\left(V_{\mathrm{oc}}\right.$ and $\left.i_{\mathrm{sc}}\right)$ were determined with the help of a carbon pot $(\log 500 \mathrm{~K})$ in the circuit of the microammeter, through which an external load was applied. The corresponding value of the potential, with respect to different current values for all the three systems, has already been studied.

It was observed that in the entire three systems $i-V$ curve deviated from their expected regular rectangular shapes. The power point (a point on the curve 
Table 3. Effect of light intensity

[azur A] $=8.0 \times 10^{-5} \mathrm{M}$; [azur B] $=9.6 \times 10^{-5} \mathrm{M}$; $\left[\right.$ azur C] $=1.6 \times 10^{-4} \mathrm{M} ;[\mathrm{NaLS}]=6 \cdot 0 \times 10^{-3} \mathrm{M}$; $[$ ascorbic acid $]=4.8 \times 10^{-3} \mathrm{M} ;$ light intensity $=10 \cdot 4 \mathrm{~m} \mathrm{~W} \mathrm{~cm}^{-2} ; \mathrm{pH}=12 \cdot 4$

\begin{tabular}{cccccc}
\hline & \multicolumn{5}{c}{ Light intensity $\left(\mathrm{mW} \mathrm{cm}^{-2}\right)$} \\
\cline { 2 - 5 } NaLS-ascorbic acid system & $3 \cdot 1$ & $5 \cdot 2$ & $10 \cdot 4$ & $15 \cdot 6$ & $26 \cdot 0$ \\
\hline Azur A Photopotential $(\mathrm{mV})$ & $712 \cdot 0$ & $745 \cdot 0$ & $770 \cdot 0$ & $810 \cdot 0$ & $950 \cdot 0$ \\
Photocurrent $(\mu \mathrm{A})$ & $135 \cdot 0$ & $152 \cdot 0$ & $160 \cdot 0$ & $176 \cdot 0$ & $188 \cdot 0$ \\
Log $V$ & $2 \cdot 8529$ & $2 \cdot 8731$ & $2 \cdot 8864$ & $2 \cdot 9084$ & $2 \cdot 9777$ \\
Azur B Photopotential $(\mathrm{mV})$ & $906 \cdot 0$ & $938 \cdot 0$ & $971 \cdot 0$ & $998 \cdot 0$ & $1018 \cdot 0$ \\
Photocurrent $(\mu \mathrm{A})$ & $165 \cdot 0$ & $170 \cdot 0$ & $185 \cdot 0$ & $196 \cdot 0$ & $215 \cdot 0$ \\
Log $V$ & $2 \cdot 9571$ & $2 \cdot 9722$ & $2 \cdot 9872$ & $2 \cdot 9991$ & $3 \cdot 0077$ \\
Azur C Photopotential $(\mathrm{mV})$ & $585 \cdot 0$ & $605 \cdot 0$ & $623 \cdot 0$ & $635 \cdot 0$ & $650 \cdot 0$ \\
Photocurrent $(\mu \mathrm{A})$ & $140 \cdot 0$ & $142 \cdot 0$ & $145 \cdot 0$ & $148 \cdot 0$ & $150 \cdot 0$ \\
Log $V$ & $2 \cdot 7671$ & $2 \cdot 7817$ & $2 \cdot 7944$ & $2 \cdot 8027$ & $2 \cdot 8129$ \\
\hline
\end{tabular}
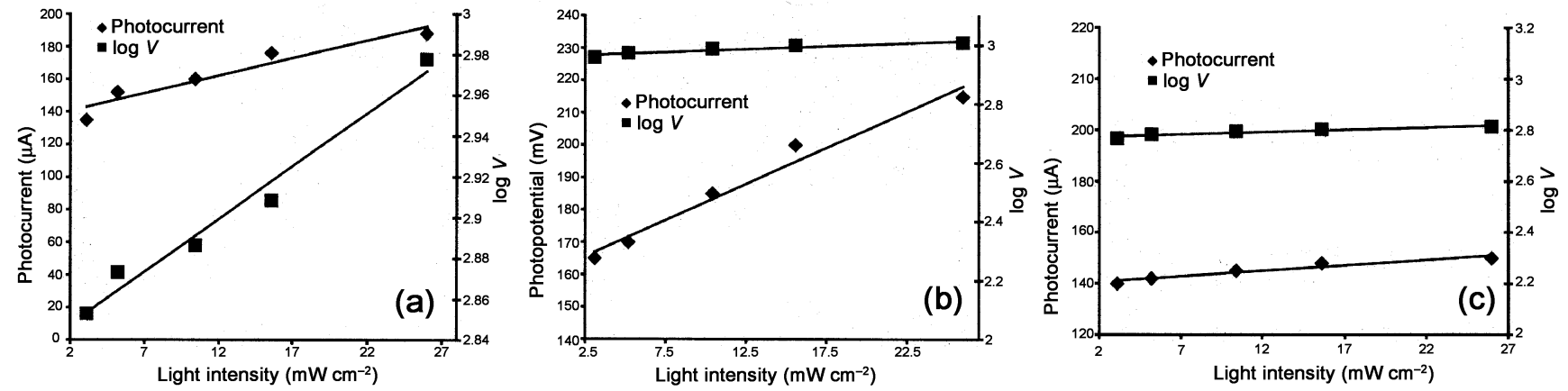

Figure 2. Variation of photocurrent and $\log V$ with light intensity for systems containing NaLS, ascorbic acid and azur A (a), azur B (b) and azur C (c).
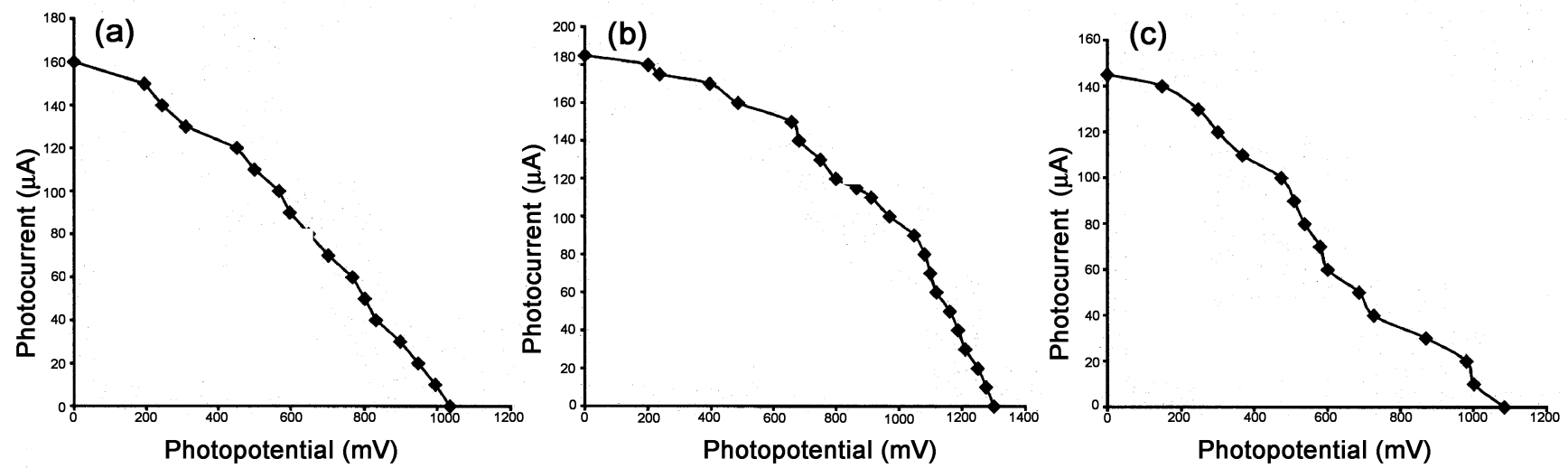

Figure 3. Current-voltage $(i-V)$ curve of the cells for systems containing NaLS, ascorbic acid and azur A (a), azur B (b) and azur $\mathrm{C}(\mathbf{c})$.

where the product of potential and current is maximum) on these $i-V$ curves was determined and their fill factors was also calculated. $i-V$ curve are given in figure 3. On the basis of fill factor calculated, the 
most efficient system is NaLS-ascorbic acid-azur B followed by NaLS-ascorbic acid-azur A and NaLSascorbic acid-azur $\mathrm{C}$ system.

\section{Performance of the cell}

Performance of photogalvanic cells was studied by applying the desired external load to obtain the potential and current corresponding to the power point after removing the source of illumination.

Time $t^{1 / 2}$ was determined after removing the source of light. It is the time taken to reach half the value of power. Performances of various cells were studied and comparative values are summarized in table 4.

On the basis of the observed data, NaLS-ascorbic acid-azur B is the most efficient system from the power generation point of view (solar energy conversion) and also the most efficient from the performance point of view (solar energy storage), followed by the NaLS-ascorbic acid-azur A and NaLS-ascorbic acid-azur $\mathrm{C}$ systems.

Properties of a photogalvanic cell with azur B are superior to those of cells with azur A and azur C, due to the presence of a trimethyl group in azur B (structure I) while azur A and C have dimethyl and mono methyl groups respectively (structures II and III). We know that methyl $\left(-\mathrm{CH}_{3}\right)$ groups show a positive inductive effect. This effect is greater in azur B dye than in azur A and azur C. Hence, azur B gives better performance than the others.<smiles>CNc1ccc2nc3ccc(=[N+](C)[O-])cc-3sc2c1</smiles><smiles>C[N+](C)([Cl+])C1C=CC2=Nc3ccc(N)cc3SC2=C1</smiles>

Azur A<smiles></smiles>

\section{Conversion efficiency of the cell}

Conversion efficiencies of all these systems were calculated using the outputs at the power point and the intensity of the incident radiation. The systems (at their optimum conditions) were also exposed to sunlight. The conversion efficiency and sunlight conversion data for these three systems are reported in table 4 .

On the basis of three observations, the highest conversion efficiency was found in the NaLS-ascorbic acid-azur B system followed by the NaLS-ascorbic acid-azur $\mathrm{A}$ and NaLS-ascorbic acid-azur $\mathrm{C}$ systems.

\section{Mechanism}

In the dark, no reaction between heterocyclic dyes and reductants takes place. It may be concluded that the redox potential of reductant (ascorbic acid) is much higher than the dyes used in the present work, as a rapid fall in potential is observed when the platinum electrode is illuminated and after some time, a constant value was obtained. On removing the source of light, the change in potential is reversed but it never reaches the initial value. It suggests that main reversible photochemical reaction is also accompanied by some irreversible side reactions.

Gomer $^{5}$, Clark and Eckert ${ }^{6}$ have discussed the electractive species in a well-established system the like the thionine iron (II) system, where ferric ions were considered as the reactive species at the dark electrode. In all the three systems, the electroactive species are the leuco dyes and dyes itself at the illuminated and dark electrodes respectively.

According to observed results, the most probable rate-determining process for $\left(i_{\text {eq }}\right)$ should be the recycling reaction of oxidation product of the reducing agent and the semi- or leuco-dyes (photosensitizers).

Some experimental evidence has been obtained by Wildes and Lichtin ${ }^{8}$ and Wyart et $a l^{10}$ supporting the participation of the leuco form of the dyes as electroactive species.

On the basis of these observations, a mechanism is suggested for the generation of photocurrent in the photogalvanic cell as below.

\subsection{Illuminated chamber}

$\mathrm{D}, \mathrm{D}^{-}, \mathrm{R}$ and $\mathrm{R}^{+}$are the dye, excited form of dye (semi or leuco form), reductant and oxidized form of the reductant respectively. 
Table 4. NaLS-ascorbic acid - azur A, B and C systems.

[azur A] $=8.0 \times 10^{-5} \mathrm{M}$; $\left[\right.$ azur B] $=9.6 \times 10^{-5} \mathrm{M}$; $\left[\right.$ azur C] $=1.6 \times 10^{-4} \mathrm{M} ;[\mathrm{NaLS}]=6.0 \times$ $10^{-3} \mathrm{M}$; [ascorbic acid] $=4 \cdot 8 \times 10^{-3} \mathrm{M}$; light intensity $=10.4 \mathrm{~m} \mathrm{~W} \mathrm{~cm}^{-2} ; \mathrm{pH}=12 \cdot 4$; temp. $=$ $303 \mathrm{~K}$

\begin{tabular}{lccc}
\hline Observations & Azur A & Azur B & Azur C \\
\hline Open circuit voltage $\left(V_{\mathrm{OC}}\right)(\mathrm{mV})$ & $1035 \cdot 0$ & $1301 \cdot 0$ & $1085 \cdot 0$ \\
Photo potential $(\Delta V)(\mathrm{mV})$ & $770 \cdot 0$ & $971 \cdot 0$ & $623 \cdot 0$ \\
Equilibrium photocurrent $\left(i_{\mathrm{eq}}\right)(\mu \mathrm{A})$ & $160 \cdot 0$ & $185 \cdot 0$ & $145 \cdot 0$ \\
Maximum photocurrent $\left(i_{\mathrm{max}}\right)(\mu \mathrm{A})$ & $190 \cdot 0$ & $215 \cdot 0$ & $180 \cdot 0$ \\
Short circuit current $\left(i_{\mathrm{sc}}\right)(\mu \mathrm{A})$ & $160 \cdot 0$ & $185 \cdot 0$ & $145 \cdot 0$ \\
Current at power point $\left(i_{\mathrm{pp}}\right)(\mu \mathrm{A})$ & $100 \cdot 0$ & $110 \cdot 0$ & $100 \cdot 0$ \\
Potential at power point $\left(V_{\mathrm{pp}}\right)(\mathrm{mV})$ & $568 \cdot 0$ & $912 \cdot 0$ & $475 \cdot 0$ \\
Power at power point $(\mathrm{PP})(\mu \mathrm{W})$ & $56 \cdot 80$ & $100 \cdot 32$ & $47 \cdot 50$ \\
Rate of generation of current $\left.(\mu \mathrm{A} \mathrm{min})^{-1}\right)$ & $19 \cdot 00$ & $26 \cdot 87$ & $18 \cdot 00$ \\
Fill factor $(\eta)$ & $0 \cdot 34$ & $0 \cdot 41$ & $0 \cdot 30$ \\
Charging time $($ min $)$ & $140 \cdot 0$ & $125 \cdot 0$ & $150 \cdot 0$ \\
$t^{1 / 2}($ min $)$ & $110 \cdot 0$ & $135 \cdot 0$ & $95 \cdot 0$ \\
Conversion efficiency $(\%)$ & $0 \cdot 5461$ & $0 \cdot 9646$ & $0 \cdot 4567$ \\
\hline
\end{tabular}

On irradiation, dye molecules attain the excited form,

$$
\mathrm{D} \stackrel{l v}{\longrightarrow} \mathrm{D}^{*} .
$$

Excited dye molecules accept an electron each from the reductant and are converted into the semi or leuco-form of the dye, and the reductant is converted into its excited form as

$$
\mathrm{D}^{*}+\mathrm{R} \rightarrow \mathrm{D}^{-} \text {(semi or leuco) }+\mathrm{R}^{+} \text {. }
$$

At the platinum electrode: The semi- or leuco-form of the dye loses an electron and is converted into the original dye molecule,

$$
\mathrm{D}^{-} \rightarrow \mathrm{D}+e^{-} \text {. }
$$

\subsection{Dark Chamber}

At counter electrode: Dye molecules accept an electron each from the electrode and are converted in to semi- or leuco-form,

$$
\mathrm{D}+e^{-} \rightarrow \mathrm{D}^{-} \text {(semi or leuco). }
$$

Finally the leuco/semi-form of the dye and the oxidized form of the reductant combine to give the original dye and reductant molecule and the cycle goes on

$$
\mathrm{D}^{-}+\mathrm{R}^{+} \rightarrow \mathrm{D}+\mathrm{R}
$$

\section{Conclusion}

Scientists have been studying the harvesting of solar energy in various forms of solar cells like photoelec- trochemical, photovoltaic and photogalvanic cells. Photovoltaic cells are widely used in most countries for conversion and storage of solar energy but owing to their low storage capacity, photogalvanic cells are preferred because they have the added advantage of inherent storage capacity.

On the basis of results obtained in present work by using three types of heterocyclic dyes (azur A, azur B, azur C), we have demonstrated the higher storage capacity of these photogalvanic cells as well as their greater electrical output in comparison to those previously prepared with dye azur B, surfactant tween 80 and NaLS, used by Genwa and Gangotri. ${ }^{19}$ In these systems, the value of conversion efficiency is $0.2177 \%$ and storage capacity is 74.0 min. Other dyes like methylene blue with oxalic acid and NaLS were used by Gangotri and Meena ${ }^{20}$ and their values of electrical output (conversion efficiency $=0.1211 \%$ and cell performance $=35 \cdot 0 \mathrm{~min}$ ) and other parameters are lower whereas the present values of electrical output are reasonably higher. Therefore these systems are more efficient than existing ones.

Efforts will be made in future to enhance both these factors along with exploring their commercial viability.

\section{References}

1. Rideal E K and Williams D C 1925 J. Chem. Soc. 258

2. Rabinowitch E 1940 J. Chem. Phys. 8551

3. Rabinowitch E 1940 J. Chem. Phys. 8560

4. Potter A C and Thaller L H 1959 Solar Energy 3 
5. Gomor R 1975 Electrochim. Acta 2013

6. Clark W D K and Eckert J A 1975 Solar Energy 17 147

7. Kaneko M and Yamada A 1977 J. Phys. Chem. 81 1213

8. Wildes P D and Lichtin N N 1978 J. Phys. Chem. 52 981

9. Hoffman M Z and Litchin N N 1979 Solar Energy 153

10. Wyart Romy, Memaeker A K D and Naslelski 1979 Nouv. J. Chem. 3303

11. Ameta S C, Jain P K, Janoo A K and Ameta R 1985 Energy J. $\mathbf{5 8} 8$

12. Ameta S C, Ameta R, Sharma D and Dubey T D 1987 Hungarian J. Ind. Chem. 15377

13. Ameta S C, Khamesra S, Gangotri K M and Seth S 1990 Z. Phys. Chem. (Leipzig) 271427
14. Gangotri K M, Regar O P, Chhagan Lal, Kalla P, Genwa K R and Meena R 1996 Int. J. Energy Res. 20 581

15. Gangotri K M, Genwa K R, Chhagan Lal, Kalla P, Reger O P and Meena R 1997 Arab. J. Sci. Eng. 22 115

16. Gangotri K M, Meena R C and Meena R 1999 J. Photochem. Photobiol. A123 93

17. Gangotri K M and Regar O P $2000 \mathrm{~J}$. Indian Chem. Soc. 77347

18. Gangotri K M and Chhagan Lal 2001 Energy Sources 23267

19. Genwa K R and Gangotri K M 2001 AFINIDAD 58 492

20. Gangotri K M and Meena R C 2001 J. Photochem. Photobiol. A141 175 